\title{
Diversidade cultural nos mercados de comunicação e cultura: um panorama das discussões e métodos de pesquisa na indústria fonográfica
}

\author{
Leonardo De Marchi ${ }^{1}$
}

Resumo

A diversidade cultural se tornou um critério importante para a formulação de políticas culturais. No entanto, a definição conceitual desse elusivo termo e o desenvolvimento de técnicas de mediação de seus níveis em mercados de comunicação e cultura constituem um grande desafio. É interessante notar que a indústria fonográfica tornou-se um laboratório de desenvolvimento de técnicas de pesquisa sobre diversidade cultural, contando, hoje, com uma vasta literatura dedicada ao tema. Contudo, na medida em que a própria indústria fonográfica se digitaliza, torna-se urgente revisar os fundamentos dessas pesquisas. Este artigo apresenta, portanto, um duplo objetivo. Por um lado, propõe uma descrição dos métodos de medição da diversidade cultural no mercado fonográfico, a partir da análise dos principais estudos dedicados ao tema. Por outro, descreve o negócio fonográfico na era digital, a fim de avaliar a necessidade ou não de revisão dos tradicionais métodos de mediação de seus níveis de diversidade cultural. Como considerações finais, aponta tópicos importantes para futuras pesquisas sobre organização do mercado de comunicação e cultura e diversidade cultural.

Palavras-chave: diversidade cultural. Indústria fonográfica. Estrutura de mercado. Métodos de pesquisa de diversidade cultural. Serviços de streaming.

\section{Cultural diversity in the markets of communication and culture: an overview of discussions and research methods in the music industry}

Abstract

Cultural diversity has become an important issue for cultural policies. Nevertheless, the conceptual definition of this elusive term and the development of techniques to measure its levels in communication and cultural markets are a great challenge. Interestingly, the recording industry became a sort of laboratory for the development of these sort of techniques, presenting nowadays a considerable literature on the subject. As the recording industry becomes digital, however, there is an urgency to revise the existing premises and instruments of measurement. The objective of the article is two fold. On the one hand, I propose a overview of cultural diversity measurement methods in the recording industry, commenting on the main papers on this topic. On the other, I describe the recording business in the digital age, in order to evaluate the necessity of reviewing those traditional methods.

1 Bolsista PNPD/CAPES do Programa de Pós-Graduação em Comunicação da Universidade do Estado do Rio de Janeiro (PPGCOM-UERJ). E-mail: leonardodemarchi@gmail.com 
As concluding remarks, I highlight some aspects for future research on the organization of the culture market and cultural diversity.

Keywords: cultural diversity. Music industry. Market structure. Methods of researching cultural diversity. Streaming services.

\section{Introdução}

As tecnologias da informação digitais e em rede têm provocado uma destruição criadora dos mercados de comunicação e cultura, notadamente de tradicionais ramos como imprensa, rádio, televisão, cinema e fonografia. A digitalização de seus conteúdos tornou obsoletos os modelos de negócios de tradicionais produtores e intermediários, os quais têm observado o surgimento de concorrentes mais bem adaptados ao ambiente digital. De negócios que funcionavam numa lógica de produção industrial, tendo intermediários que selecionavam o que deveria ser publicado (em jornais, revistas, discos ou transmitidos via rádio ou televisão), passou-se a um sistema em que a produção de conteúdos foi atomizada e a distribuição se tornou a fase crítica para o acesso e usufruto dos bens culturais. Ao invés de produzir modelos similares em larga escala e transportálos para lojas físicas, hoje se faz necessário cultivar redes de usuários, os quais se encarregarão da disseminação dos conteúdos digitais. Com o notável barateamento do estoque e distribuição dos conteúdos digitais, a tendência do mercado digital seria se converter numa grande coleção de mercado de nichos, em que todo tipo de produto encontraria seu consumidor, configurando um tipo de economia de cauda longa (ANDERSON, 2006). O problema passaria a residir, portanto, na capacidade de diferentes produtores acessarem seu público, imerso num ambiente de abundante informação, para negociarem diretamente seus produtos. Isso acarreta uma transformação profunda nas estruturas de mercado desses ramos do comércio de bens culturais, abrindo toda uma série de questões sobre a dinâmica desses mercados digitais.

Entre essas questões, abre-se espaço para o debate sobre diversidade cultural. Termo cuja definição é propositalmente frouxa para que possa se adequar a diferentes interesses, a demanda pelo respeito à diversidade cultural pode ser justificada seja para defender o ideal liberal do mercado de ideias, seja para defender políticas de afirmação cultural de grupos minoritários e/ou subalternos dentro de determinada sociedade. Uma vez consolidada na agenda política dedicada à regulação dos mercados de comunicação e cultura (sobretudo após a adoção do termo pela UNESCO), tornou-se imperativo desenvolver técnicas para a medição da diversidade cultural nos diferentes ramos da economia da cultura Essa tarefa provaria ser altamente difícil. Não apenas seria necessário encontrar um consenso conceitual para o termo, como também desenvolver ferramentas de análise adequadas às especificidades de cada mercado de comunicação e cultura. Afinal, muitos desses mercados, ao contrário de ramos mais estabelecidos das indústrias de bens utilitários, possuíam poucas informações prontas para análise e, em não poucos casos, tratava-se de informações de baixa confiabilidade.

É interessante notar que, entre tais mercados, a indústria de discos, ou fonográfica, tornou-se um laboratório propício para o desenvolvimento de técnicas de pesquisa sobre diversidade cultural. Afinal, trata-se de uma indústria de alcance global, que experimenta uma dinâmica intensa de transformação de suas estruturas produtivas, além de ser um negócio de cultura que apresenta uma farta (e razoavelmente precisa) quantidade de informação sobre o consumo de seus produtos, através de publicações informadas pelas associações da própria indústria. Assim, desde o pioneiro trabalho de Richard Peterson e David Berger (1975) até a análise tripartite de Heritiana Ranaivoson (2010), está disponível um importante conjunto de pesquisas que apresentam um panorama bastante interesse do debate sobre diversidade cultural e estrutura do mercado de discos físicos.

Contudo, na medida em que a indústria 
fonográfica se digitaliza, torna-se urgente revisar os fundamentos das pesquisas anteriores. Afinal, elas se dedicaram a um negócio industrial de produção de discos físicos; agora, trata-se da circulação de conteúdos digitais, o que implica a aparição de novos players e hábitos de consumo. Além disso, os serviços de streaming fazem um uso intensivo de algoritmos para a recomendação musical. Mais do que um serviço automático submisso às demandas que partem dos usuários, tais algoritmos são agentes que apresentam uma série de arquivos, preterindo tantos outros, de acordo com os cálculos que fazem da mineração de dados. Assim, como isso poderia afetar a diversidade cultural do mercado fonográfico digital? Ou, ainda, como seria possível verificar a manifestação da diversidade cultural na era de algoritmos complexos para prescrição musical? Para começar a responder tais questões, é preciso avaliar, antes, como se tratou a questão da diversidade cultural na indústria fonográfica na época industrial desse negócio e quais são as principais diferenças que se apresentam atualmente.

Este artigo apresenta um duplo objetivo. Por um lado, propõe-se uma revisão dos métodos de medição da diversidade cultural no mercado fonográfico, a partir da análise dos principais estudos dedicados ao tema. Por outro, descrevese o que se tornou o negócio fonográfico, a fim de avaliar a necessidade ou não de revisão dos tradicionais métodos. $\mathrm{O}$ artigo se divide em duas partes. Na primeira, revista-se a literatura sobre estrutura do mercado fonográfico e diversidade cultural, através dos textos referenciais. $\mathrm{Na}$ sequência, comentam-se as principais transformações no modus operandi do mercado fonográfico na era digital, fazendo uma breve crítica a argumentos liberais que, num momento, celebraram acriticamente a possibilidade dos mercados de comunicação e cultura de abrigarem diferentes tipos de expressões culturais (notadamente, a teoria da cauda longa). Como considerações finais, apontam-se aspectos importantes para futuras pesquisas sobre organização do mercado de cultura e diversidade cultural.

\section{Os estudos sobre diversidade cultural na indústria fonográfica: principais métodos de análise}

Pode-se dizer que a diversidade cultural tornou-se um critério importante para políticas de comunicação e cultura contemporâneas, ainda que não sem controvérsias seja sobre sua definição, seja sobre utilização política. Em sociedades de tendência política liberal, o termo materializa o princípio do "mercado de ideias", de acordo com o qual a maior diversidade de bens culturais disponível permite fomentar diferentes objetivos desejados: desde a escolha racional dos consumidores, o pluralismo cultural, o exercício da cidadania até o funcionamento correto do sistema democrático (NAPOLI, 1999; McQUAIL, 1998).

Desde a década de 1990, contudo, a ideia de diversidade cultural ganhou outra dimensão, ao ser incluída em tratados políticos e comerciais internacionais como certa forma de "antídoto" ao risco de "homogeneização" das culturas nacionais diante de um mercado de bens culturais globalizado. Tal ênfase resultou de uma disputa política entre os Estados Unidos e um grupo de países francófonos, liderados por Canadá e França. Em meio às negociações para facilitar e institucionalizar o comércio global, na chamada Rodada do Uruguai da Organização Mundial do Comércio (OMC) houve um embate entre os representantes estadunidenses, canadenses e franceses sobre a inclusão dos chamados bens culturais (artes e entretenimento) nos acordos de livre-comércio. Enquanto aqueles desejavam incluir esse tipo de mercadoria entre os artigos a serem livremente comercializados entre os países, sem que quaisquer proteções alfandegárias se impusessem, a liga liderada pelos países francófonos se opôs terminantemente, afirmando que os bens culturais não apresentavam a mesma natureza utilitária de outros itens que constavam das negociações, pois estariam vinculados à formação de identidades nacionais. Para garantir a continuidade de suas políticas culturais diante de um cenário de total desregulação neoliberal, 
os franceses chegaram a cunhar o conceito de "exceção cultural" (l'exception culturelle). No entanto, como a expressão se restringiu ao mundo da francófono, houve todo um esforço diplomático para que a discussão alcançasse uma plataforma global, com força política, como a UNESCO. A partir daí, o termo adotado foi "diversidade cultural". Como observa Martí Petit (2012, pp.220-3), a recepção desse debate pela UNESCO permitiu que outros países europeus interessados no tema (como os países compostos por diferentes nações, as quais apresentam demandas independentistas) se engajassem individualmente (já que na OMC eles eram representados como União Europeia), além dos países em desenvolvimento que mostravamse preocupados com o avanço dos produtos culturais estadunidenses sobre seus mercados nacionais.

Ao ser encampado pela UNESCO, o termo ganhou um sentido ampliado, aproximando-se do de direitos culturais (STOCZKOWSKI, 2009; UNESCO, 2002, 2005). Nesse caso, diante de uma articulação econômica crescente entre diversos países, baseada em (1) políticas econômicas que minariam políticas locais de desenvolvimento e (2) no livre fluxo de capital e trabalho, além da consolidação de um mercado global de bens culturais produzidos em larga escala $\mathrm{e}$ fundamentados em um estilo de vida baseado no consumo de algumas marcas transnacionais, a UNESCO reinterpretaria sua preocupação com uma unidade da humanidade, enfatizando a necessidade da preservação e fomento justamente $\mathrm{da}$ diferença entre povos e grupos sociais, ou em uma expressão, protegendo e fomentando a diversidade cultural.

Esse breve resumo permite entrever que definir tecnicamente o que se entende por "diversidade cultural" a fim de medir o grau de sua manifestação em mercados de comunicação e cultura específicos são dois problemas extremamente complexos em si e que, para piorar a situação, devem ser forçosamente articulados. Como sustentar políticas públicas de defesa e promoção da diversidade cultural sem saber como ela se manifesta nos mercados de comunicação e cultura?

É interessante notar que um dos mercados de comunicação e cultura mais analisados é o fonográfico. Afinal, trata-se de um objeto de estudo que cobre diversos parâmetrosimportantes para embasar tais pesquisas: (1) trata-se de uma indústria de alcance global, presente em países de distintos níveis de desenvolvimento; (2) a música gravada se tornou um produto cultural altamente disseminado em muitas sociedades; (3) é uma indústria que experimenta uma dinâmica intensa de transformação de suas estruturas produtivas, além de ser (4) um negócio de cultura que apresenta uma farta (e razoavelmente precisa) quantidade de informação sobre o consumo de seus produtos, o que não ocorre com a indústria de cinema, nem a de livros, por exemplo. Atualmente, pode-se encontrar um importante corpo de pesquisas que apresentam metodologias comprovadamente eficazes para medir a diversidade cultural. A seguir, apresentase um resumo desses estudos.

A literatura sobre o tema da diversidade cultural no mercado fonográfico concorda em que o trabalho seminal é o dos sociólogos Richard Peterson e David Berger (1975) acerca da relação entre estrutura de mercado, inovação e diversidade no mercado fonográfico. Nesse paper, os autores buscavam pensar a questão através da teoria dos ciclos econômicos, aplicando-a à indústria fonográfica ${ }^{2}$. O texto vinha a se somar ao esforço de outros estudiosos que rejeitavam o pressuposto de que a produção de bens culturais nas sociedades capitalistas tendia inexoravelmente à homogeneidade dos

2 Os economistas concordam em que a taxa de inovação numa indústria é diretamente proporcional à estrutura de um mercado. Em seu livro sobre ciclos econômicos, Schumpeter havia afirmado que apenas um mercado oligopolista teria empresas com recursos financeiros suficientes para financiar a inovação e repassar esses altos custos para o consumidor. Outros economistas, porém, afirmam o contrário: apenas quando um mercado é constituído por um grande número de empresas que competem entre si é que a inovação encontra um molde institucional capaz de fomentá-la. 
produtos, como sustentava a abordagem da Escola de Frankfurt à indústria cultural. Pelo contrário, entendia-se que o tipo de organização que assume um determinado mercado de cultura pode deixá-lo mais ou menos propenso à inovação e à diversidade cultural, pressuposto que exigia estudos empíricos sobre a estruturação de cada ramo das indústrias culturais. Assim, buscava-se verificar se a estrutura do mercado (aspectos da interação da oferta e demanda, organização da produção e sua relação com a natureza e níveis de consumo) gerava impacto sobre o que os autores classificaram de "inovação" e "diversidade" de produtos. Os termos merecem atenção: "inovação" equivalia a "gêneros musicais", enquanto "diversidade" designava "variedade das letras" ou "diferenças" (melódicas, harmônicas, rítmicas) entre as músicas de sucesso.

Para tanto, analisaram-se as listas dos dez compactos (singles) mais vendidos, segundo a Revista Billboard ${ }^{3}$, entre os anos de 1948 e 1973, nos Estados Unidos. Através da análise da variação das gravadoras e de novos artistas que alçavam o chamado Top 10, demonstraram como o marcante período de inovação musical que se experimentou entre os anos 1950 e 1960 (período de emergência e consolidação do rock n 'roll) havia sido precedido por uma reestruturação do mercado de comunicação e cultura. Entre 1955 e 1959, houve um momento de flexibilização da produção (antes, concentrado em quatro grandes gravadoras) e a emergência de mais gravadoras independentes. Uma das principais razões para isso, afirmavam, teria sido o surgimento da televisão e a conseguinte transformação do radio de um grande mercado nacional, controlado por um reduzido número de estações, para um conjunto de nichos de mercado, conduzidos por estações menores e especializadas. Com isto, as companhias discográficas independentes tiveram a oportunidade de acessar mais facilmente as estações de rádio para promover seus produtos.
O que ocorreu na sequência foi, de acordo com o argumento, um aumento importante do número de gravadoras que emplacaram pelo menos um artista na parada dos dez compactos mais vendidos. Este número quadruplicou em relação ao período anterior e entre as gravadoras que constavam com mais de um artista, triplicou. No entanto, entre os anos de 1970 e 1973, as grandes gravadoras passaram a comprar as empresas independentes, gerando uma nova onda de concentração de mercado, que se refletiu na baixa variedade de empresas que emplacaram alguma gravação nas paradas de sucessos naquele período.

Peterson e Berger concluíram que havia uma relação inversa entre concentração de mercado e inovação e/ou diversidade cultural. Isto é, mesmo que haja certa competição entre grandes empresas em um estado de oligopólio, a tendência é que tais companhias inovem com moderação em suas linhas de produtos, uma vez que seu objetivo é a conquista de uma grande parcela de um mesmo mercado. Inversamente, quando há diversas firmas competindo, a tendência é que se criem segmentos de público (nichos) através da constante inovação dos produtos. Assim, "inovação" e "diversidade" equivaler-se-iam, tão logo houvesse um alto índice de competição empresarial.

A teoria dos ciclos econômicos seria retomada posteriormente por vários autores, com o intuito de dar sequência ao método de Peterson e Berger. Assim, Rothenbuler e Dimmick (1982) analisaram as paradas de 1974 a 1980, e, em seguida, Burnett e Weber (1989) atualizaram a pesquisa até 1986. Porém, esses pesquisadores já observavam que a indústria fonográfica assumira uma organização distinta entre as décadas de 1970 e 1980. Ao invés das grandes gravadoras verticalizarem sua produção (isto é, internalizarem as diversas partes da cadeia produtiva, centralizando as tomadas de decisões),

3 Editada pela primeira vez em 1894, a Revista Billboard era dedicada, inicialmente, ao mercado publicitário. A partir dos anos 1950, passou a se dedicar ao mercado de música, publicado as paradas de discos (álbuns e compactos) mais vendidos nos Estados Unidos. 
tais companhias passavam a estabelecer acordos com empresas independentes a fim de que estas produzissem discos e firmassem parcerias com as majors para a distribuição dos produtos físicos. Começa-se, assim, a notar que as fronteiras entre o que é mainstream e o independente se tornavam porosas. Nesse cenário, observaram os autores em sua conclusão, seria provável que a relação entre estrutura de mercado e inovação/ diversidade no mercado de música variasse num futuro próximo.

Essa previsão foi concretizada, como se verifica no trabalho de Paul D. Lopes (1992). Lopes partiu de outra pergunta: ao invés de querer saber se havia ou não uma inequívoca relação direta entre concentração de mercado e inovação estética/ diversidade cultural, seu interesse residia em saber se havia a possibilidade de haver uma alta concentração de mercado sem gerar, com isso, um baixo nível de inovação e de diversidade. Outra inovação interessante do trabalho de Lopes foi a decisão de concentrarse não apenas na lista dos dez compactos mais vendidos, mas nas listas dos 100 compactos e álbuns (discos contento mais de quatro músicas de um ou vários artistas) mais vendidos entre 1969 e 1990. De acordo com o próprio autor, a ampliação dos objetos de análise se deveu ao fato de que, para a indústria fonográfica a partir dos anos 1970, o formato de "álbum" tornara-se mais importante do que o de compactos. Desta forma, uma análise sobre níveis de concentração e diversidade cultural no mercado de música não poderia deixar de levar em consideração a participação das empresas fonográficas no campo dos álbuns mais vendidos.

O resultado obtido demonstrava que: o movimento de concentração de mercado continuou com força ao longo dos anos 1970 e 1980, mas o número de gravadoras e selos que emplacaram algum sucesso entre os anos 1980 e 1990 manteve-se estável e até aumentou em certos períodos. Por exemplo, gêneros como o rap ou a new wave passaram a ter uma participação importante nas paradas de sucesso, mesmo sendo introduzidos por gravadoras independentes (ainda que ligadas às grandes por acordos de distribuição/divulgação). Isso ocorreu ao mesmo tempo em que a concentração do mercado de discos aumentava significativamente: esse foi o período em que o mercado passou a se concentrar em quatro corporações fonográficas, as quais detinham de $70 \%$ a $80 \%$ da venda de música gravada no mercado internacional de discos. Tais dados levaram-no a concluir que a adoção de uma organização mais flexível de produção (open system), como a rotulou, pelas grandes gravadoras permitira manter o nível de diversidade musical no mercado mesmo diante da brutal concentração das vendas.

O método de análise das paradas de sucesso da Billboard, ainda que importante, estava longe de ser capaz de alcançar algum consenso sobre como se medir a diversidade cultural de algum mercado cultural. Assim sendo, outras técnicas foram buscadas. Em um trabalho menos conhecido, mas não menos importante, Michael Christianen (1995) propôs abordar esta discussão a partir de outra técnica de pesquisa. Seu argumento era o de que a técnica utilizada por todos os autores anteriores não era representativa de tudo o que se produzia em um determinado mercado de música, privilegiando apenas o polo do consumo (em detrimento da produção). A maneira mais apropriada de se avaliar a questão seria analisar toda a produção de discos em um contexto, durante determinado período. Nesse sentido, analisou a produção de discos na Holanda, entre os anos de 1975 e 1992. Ao invés de se basear no número de aparições de selos e empresa nas paradas de sucesso, Christianen dividiu sua análise em três eixos: (I) gêneros musicais (rock, pop, rap, etc.); (II) repertório (inédito, reeditado, nacional, internacional); (III) número de gravadoras e selos. Diferentemente dos autores anteriores, a definição deste autor para medir a "diversidade cultural" no mercado holandês de música não se referia às paradas de sucesso, mas (a) à disponibilidade de música para os consumidores no grande mercado e (b) à disponibilidade de artistas em cada gênero musical. "Inovação" equivalia, por seu turno, ao número de novos artistas que a cada ano acessavam o mercado de música. 
Sua análise indicava que os níveis de diversidade cultural e inovação no mercado de música alcançaram o patamar mais elevado nos anos 1990, quando uma forma mais flexível de produção de fonogramas foi adotada pelas gravadoras. Mais importante do que isto, porém, foi que o autor comprovava que, ao longo do período estudado, o número de lançamento de novos artistas por grandes gravadoras havia diminuído dramaticamente (de 60\% nos anos 1970 para 25\% nos 1990), na mesma medida em que crescia a participação de empresas independentes. Afinal, também Christianen confirmava as conclusões de Burnett e Weber (op. cit.) e Lopes (op. cit.): uma estrutura mais dinâmica de produção fonográfica ampliava a diversidade cultural e os níveis de inovação no mercado de música. Mas também aportava uma nova e importante informação: cada vez menos as grandes gravadoras controlavam diretamente a inovação musical e a diversidade cultural no mercado de música.

Todos esses trabalhos compartilham, porém, de um mesmo problema: baseiam-se numa perspectiva dual de análise. Basicamente, contrasta-se diversidade de produtos que aparecem nas listas de compactos e/ou discos mais vendidos com a estrutura do mercado fonográfico no período estudado. Tais parâmetros seriam suficientes para medir a potencialidade de artistas e expressões culturais que podem atingir um mercado de música nacional? Ou o resultado estaria enviesado por se concentrar nas duas pontas do ciclo produtivo? Esse tipo de questionamento acarretou o desenvolvimento de uma metodologia mais sofisticada para medir a diversidade cultural: o modelo tripartite.

O modelo tripartite foi emprestado dos estudos de inovação e economia, nomeadamente o desenvolvido por Andrew Stirling (1998). Discutindo a importância do termo "diversidade" (tecnológica, no caso) na teoria econômica contemporânea, esse pesquisador afirma que sua medição nos mercados deve considerar três aspectos (STIRLING, 1998, p. 39-40):

a) Variedade: número de categorias nas quais a quantidade em questão pode ser particionada (por exemplo: o número de opções tecnológicas funcionalmente morfologicamente ou operacionalmente distintas oferecidas em paralelo num mercado).

b) Balanço: refere-se às "cotas de mercado" de cada uma das opções tecnológicas.

c) Disparidade: refere-se à natureza e ao grau em que as próprias categorias são diferentes umas das outras.

Como observa Luis Albornoz (2017, p. 199), modelo de Stirling foi adotado pelo Departamento de Estatística da UNESCO para aplicação nos mercados de comunicação e cultura, a fim de analisar os níveis de diversidade (nesse caso, cultural). Para tanto, contudo, os mesmos termos assumiram os seguintes sentidos:

a) Variedade: quantidade de gêneros culturais (por exemplo, no mercado de livros, isso pode se referir a gêneros como ficção, teoria, quadrinhos etc.).

b) Balanço: proporção de mercado, frequência ou qualquer medida de proporção de um tipo particular dentro de uma população.

c) Disparidade: refere-se ao grau em que as categorias de gênero cultural são diferentes umas das outras.

Esse modelo tem sido testado em diferentes mercados e contextos nacionais por diversos pesquisadores. No caso da música gravada, foi aplicado de forma notável por Heritiana Ranaivoson (2010).

O modelo tripartite permitiu a Ranaivoson incluir uma série de dados ausentes das análises anteriores. Desde o princípio, o autor definiu que um sistema é mais diversificado quanto mais variedade, equilíbrio e/ou disparidade existir. Além disso, estabeleceu que todo mercado tem dois tipos de diversidade: a diversidade oferecida pelos produtores e a diversidade de produtos utilizada pelos consumidores. Finalmente, a diversidade cultural depende de interações complexas entre a diversidade de produtores, produtos e consumidores. Logicamente, sua definição de "diversidade cultural" contempla: (1) a variedade, o equilíbrio e a disparidade de 
produtos na forma como são disponibilizados no mercado e, depois, consumidos, (2) diversidade de produtores, de acordo com seu potencial poder de mercado e a forma como esse poder é expresso (estrutura de mercado) e (3) diversidade dos consumidores, no que diz respeito aos seus gostos e identidades diferentes (ibid., p. 218). Além disso, ampliaram-se os dados utilizados para incluir condições sociais, demográficas e econômicas (renda per capta, PIB, entre outras categorias) das populações. Outro aspecto que torna seu trabalho excepcional é o escopo da pesquisa: analisaram-se 69 países em 5 continentes ${ }^{4}$.

Suas conclusões informam que também em nível internacional: (1) o sistema flexível de produção fonográfica favorece a diversificação de produtos disponíveis no mercado, (2) a concentração da distribuição pode levar a uma maior variedade de produtos consumidos (o que não significa que a concentração da distribuição e a diversidade de produtos sejam sempre diretamente proporcionais) e que (3) condições sociais, demográficas e econômicas apresentam uma variedade de influências diretas e indiretas tanto sobre a oferta de produtos quanto sobre as escolhas dos consumidores, ainda que nem sempre de forma óbvia 5 .

Sem constrangimentos, pode-se afirmar que a pesquisa coordenada por Ranaivoson encerra um ciclo de pesquisas sobre diversidade cultural no mercado fonográfico analógico. Não é que todas as questões tenham sido respondidas, mas, sim, que as possibilidades de pesquisa foram radicalmente ampliadas a fim de dar conta de um objeto conceitualmente complexo. Mais do que isso, as hipóteses sobre o polo de produção fonográfica parecem ter sido esgotadas: o sistema flexível de produção permite, sem dúvida, uma ampliação do número de artistas nos mercados em que é aplicada.

Não obstante, a digitalização do mercado fonográfico implicou uma transformação qualitativa do objeto de pesquisa. A reorganização do mercado fonográfico através de plataformas digitais (iTunes, Spotify, YouTube, entre outros) e agregadores de conteúdos (The Orchid, Believe Digital, One RPM, AltaFonte, CD Baby, entre outros) faz com que a conexão entre produção e consumo seja realizada na circulação dos conteúdos. Sendo assim, a separação entre as partes, conforme pensado nas pesquisas acima descritas, perde seu sentido, isso é, a produção não pode deter mais o centro das atenções. Além disso, os sistemas de recomendação de conteúdos utilizados por tais intermediários assumem um inusitado protagonismo. Os algoritmos dessas plataformas não fazem apenas o que os usuários demandam; eles atuam sobre as próprias escolhas dos usuários, sendo determinantes para o acesso aos conteúdos e, por conseguinte, sobre a inovação de produtos e a diversidade cultural do mercado fonográfico digital. Como analisar, portanto, a diversidade cultural nesse novo contexto?

Desafios para a diversidade cultural na era digital: da cauda longa à recomendação musical em serviços de streaming

No final dos anos 1990, a emergência de tecnologias digitais e em rede de reprodução sonora apresentou abruptamente um novo cenário para a indústria fonográfica. Diante da articulação entre de reprodutores de arquivos digitais de música com interfaces amigáveis (como o Winamp), arquivos digitais compactos de som (como o MP3) e programas de compartilhamento

4 Porém, com dados de segunda mão, obtidos com as associações nacionais e internacional da indústria fonográficas. Esses dados nem sempre são obtidos de forma confiável, valendo-se demasiadamente de estimativas. Para completar tal base de dados, Ranaivoson (2010) também se valeu de informações emitidas pela Divisão de Estatística das Nações Unidas (UNSD) e pelo Banco Mundial.

5 Por exemplo, identificou-se que a diversidade cultural não é necessariamente a mais elevada nos países mais favorecidos. Particularmente, um índice mais elevado de desenvolvimento humano leva à menor diversidade fornecida (ibid., p. 2245). 
de arquivos entre pares (peer to peer, ou P2P), os tradicionais atores da indústria fonográfica observaram, boquiabertos, a passagem de uma economia de natureza industrial (a produção em larga escala de fonogramas físicos) para uma economia de redes ${ }^{6}$, baseada em serviços de acesso à informação (arquivos digitais de música). Isso colocou em questão a função dos tradicionais mediadores do mercado de fonográfico: gravadoras, leis de direitos autorais e lojas de discos pareciam ter se tornado, de repente, dispensáveis num cenário de acesso direto a qualquer tipo de música que se desejasse. Isso provocou toda uma revolução na maneira de conceber o negócio fonográfico (DE MARCHI, 2016).

Num primeiro momento, a internet parecia concretizar a ideia neoliberal da completa desintermediação do mercado de música: sem a necessidade de gravadoras, todo artista poderia acessar diretamente seus ouvintes, estabelecendo relações de confiança mútua através de comunidades virtuais (KUSEK; LEONHARD, 2005). Essa perspectiva teve efeitos concretos no mundo dos negócios: muitos artistas recusaramse a assinar contratos com gravadoras, confiando em seus websites para acessar diretamente seus consumidores (DE MARCHI, op. cit.). Tal momento permitiu leituras otimistas também sobre a diversidade cultural no mercado fonográfico: sem os tradicionais gatekeepers (intermediários que selecionam quem participa ou não de um mercado), o mercado de música parecia não ter barreiras econômicas, nem de poder, para qualquer tipo de artista e de música.

Do ponto de vista econômico, essa atitude refratária aos tradicionais mediadores do mercado de música apoiava-se na teoria da cauda longa (Long Tail), de Chris Anderson (2006). Nesse best seller da década de 2000, o autor apresenta uma arguta explicação sobre as transformações econômicas no mercado digital através de uma análise de gráficos de curva de demanda. Demonstra-se, assim, que com a digitalização dos bens e dos canais de distribuição dos mesmos há: (a) uma redução drástica nos custos de armazenamento e distribuição de bens (uma vez que estão todos digitalizados, não se faz necessário desenvolver uma estrutura física para abrigá-los; apenas se faz necessário ampliar as possibilidades técnicas de distribuição dos conteúdos), (b) a ampliação a baixo custo do mercado, permitindo um aumento significativo da produção de bens, que tendem a se especializar em mercados de pequena e média extensão (nichos) e (c) o aumento da oferta de bens propicia a todo produtor encontrar seu consumidor, que por seu turno pode realizar escolhas racionais sobre o que deseja, uma vez que dispõe de dispositivos de busca que lhes permitiria acessar toda informação necessária sobre o produto desejado.

Ainda que não se tenha explorado tal conexão, é interessante notar que tal argumento se encaixa perfeitamente no de autores liberais sobre as tecnologias digitais. Tome-se, por exemplo, o notório argumento de Gates (1995), em seu momento de ideólogo das novas tecnologias da comunicação, sobre o "capitalismo sem força de atrito" (frictionless capitalism). Com isto, o autor queria dizer que as tecnologias digitais em rede diminuem os custos divulgação, distribuição e armazenamento das informações, permitindo que cada consumidor possa encontrar de forma direta e clara o que quer e negociar até alcançar o preço mais baixo, cumprindo assim

6 Economistas como Carl Shapiro e Hal Varian (1999, p. 204 et seq.) estabelecem uma definição de "economia de redes" em contraposição ao que se convencionou rotular de "economia industrial”. Assim, para tais autores, a economia industrial se caracteriza pela organização de estruturas produtivas comandadas por grandes empresas, verticalizadas e controladas por forte burocracia, que produziam modelos em série para mercados de escala (economia de escala controladas pela oferta), tendendo a uma estrutura de mercado oligopólica. Em contraste, a "economia de redes" se caracterizaria uma organização horizontal entre os nodos, funcionando através de uma dinâmica de feedbacks positivo e negativo. Nesse sentido, afirmam, "o valor de ligar-se a uma rede depende do número de outras pessoas já conectadas a ela" (ibid., p. 205). Assim, sua estrutura de mercado se caracteriza por monopólios temporários e economia de escala controladas pela demanda. 
a promessa de eterno retorno dos pequenos mercados tradicionais sobre os quais versavam os economistas clássicos ${ }^{7}$. Ou seja, as tecnologias da informação e da comunicação concretizariam a utopia liberal de um mercado de competição perfeita.

O livro de Anderson é a forma mais sofisticada deste argumento, na medida em que apresenta um caso concreto. O que importa é, no entanto, que o substrato ideológico dessas duas obras é o mesmo: as tecnologias da informação digitais e em rede revolucionam a maneira de fazer negócio, desmanchando no ar as antigas estruturas que engessavam as negociações entre produtores e consumidores. Isso abriria espaço para um livre mercado no qual os indivíduos racionais podem fazer suas próprias escolhas $\mathrm{e}$ negociações diretamente. $\mathrm{O}$ que se subentende dessa perspectiva é que a diversidade cultural nos mercados de cultura estaria garantida, pois todos os produtores têm condições de acessar o mercado sem vexações impostas por agentes economicamente mais poderosos. A importante conclusão desse raciocínio é que políticas de proteção e fomento da diversidade cultural não são necessárias, pelo contrário, pois as leis do mercado digital já garantiriam espaço para as diferentes manifestações culturais.

Infelizmente, Anderson não apresenta qualquer reflexão sobre como o mercado digital se estrutura, em torno de quais empresas e como estas afetam a dinâmica da produção e do consumo de bens no mercado digital. Tampouco, interessam-lhe como produtores e consumidores podem se encontrar e negociar num contexto de abundância de informações. Isso é, qualquer consideração sobre os novos intermediários do mercado digital (sites de buscas ou seus algoritmos) é sumariamente desconsiderada. Assume-se simplesmente que o livre-mercado estabelecido pela mudança técnica acarreta muitas opções de consumo.
Essa concepção liberal também afeta a percepção sobre diversidade cultural: está claro que, nesse contexto de desintermediação, há espaço para todo tipo de produção musical. Como expressam de maneira precisa Davis Kusek e Gerd Leonhard:

\begin{abstract}
O acesso à música nunca foi tão fácil, e a música nunca foi prosperou tanto em níveis tanto regionais quanto globais. Rock, intérpretes/ compositores, bluegrass, hip-hop, heavy metal, versões e remixes de DJ, músicas étnicas de toda variedade, incluindo música brasileira, cubana e africana, são apenas alguns exemplos de gêneros musicais que estão gozando de enorme popularidade hoje em dia. A internet, na verdade, todo tipo de rede digital, está revirando os gêneros de nicho, alçando-os do fundo para o topo [do mercado] (KUSEK; LEONHARD, 2005, p. 7, tradução própria).
\end{abstract}

Após as intensas emoções da década de 2000, estruturada em torno da bipolaridade entre o pânico da "crise da indústria fonográfica" e o otimismo da "revolução da música digital", a década de 2010 apresentaria cenário bastante diferente. Após anos de gastos com custosos (e nem sempre efetivos) processos contra programas de compartilhamento de arquivos digitais (P2P) ou usuários individualmente, os tradicionais agentes da indústria fonográfica decidiram agir ativamente e apoiar startups de tecnologia que pretendiam desenvolver negócios formais de distribuição de música digital. Surgem os serviços de streaming de música, como Spotify, Deezer, Rdio, Apple Music, entre outros, contando com o apoio dos principais players da indústria fonográfica para alavancar o novo modelo de negócio. Tecnicamente, os serviços de streaming foram os únicos capazes de estabelecer uma competição com os programas de P2P. Afinal, eles compreenderam as dinâmicas de uma economia em rede e as demandas do

7 Como afirma textualmente este autor: “a estrada [da informação] ampliará o mercado eletrônico e fará dele o intermediário universal e definitivo. Com frequência, as únicas pessoas envolvidas numa transação serão o comprador e o vendedor. [...] Isso nos conduzirá a um novo mundo, de um capitalismo com pouca força de atrito e baixo custo administrativo, no qual a informação de mercado será abundante e os custos de transação, baixos.” (GATES, 1995, p. 200). 
público de conteúdos digitais, passando a oferecer acesso a um número expressivo de arquivos de música (sempre na casa dos milhões), o que lhes permitia cobra um preço por mensalidade relativamente baixo (cerca de US\$ 10) (KISCHINHEVSKY; VICENTE, DE MARCHI, 2015). Ao mesmo tempo, cumpriam com as duas demandas dos titulares dos direitos autorais das obras licenciadas: impediam os usuários de baixarem individualmente os arquivos para os intercambiarem entre si e pagavam royalties aos titulares dos direitos autorais e fonomecânicos.

É verdade que os serviços de streaming não pacificaram todas as disputas dentro da indústria fonográfica. Tampouco seu modelo de negócio provou ser sustentável em termos econômicos: pelo contrário, a maior parte dessas empresas ainda é deficitária justamente devido às altas quantias pagas aos titulares de direitos autorais (KISCHINHEVSKY, VICENTE, DE MARCHI, op. cit.). Não obstante, é inegável que eles estabeleceram algum nível de estabilidade sobre o que pode ser o comércio de fonogramas digitais, a partir do qual se torna possível discutir cenários concretos para a indústria.

Um olhar atento ao funcionamento dessas plataformas digitais indica que elas apresentam uma importante novidade: o uso intensivo de algoritmos complexos. Em particular, destacamse os sistemas de recomendação de música para os usuários. Afinal, eles operam um papel determinante na realização do gosto dos usuários das plataformas digitais.

É preciso ter em conta que os sistemas de recomendação operam na linguagem dos algoritmos, cuja característica fundamental é a função recursiva ${ }^{8}$. Como a definem Paolo Totaro e Domenico Nino,

[...] o conceito de [recursividade] pode ser representado graficamente agrupando-se a sequência já realizada no passo anterior. Assim, o sucessor de 0 (o conjunto vazio) é $\{0\}$. O sucessor do último é o conjunto obtido ao se agregar os elementos gerados anteriormente, isto é, $\{0,\{0\}\}$. O sucessor disso é $\{0,\{0\},\{0,\{0\}\}\}$, e assim por diante. Portanto, um processo recursivo, uma vez iniciado, gera nada mais do que uma repetição da mesma operação. No entanto, os resultados desta operação não são independentes um do outro, simplesmente porque eles estão incorporados um ao outro (TOTARO; NINO, 2014, p. 31, tradução própria).

No caso dos sistemas de recomendação de música, os algoritmos das plataformas de música entregam conteúdos digitais de maneira personalizada, construindo uma cadeia de informações cuja lógica reside em integrar informações provenientes:

a) do gosto de cada usuário;

b) metadados inseridos por produtores e/ ou agregadores de conteúdo;

c) gosto de outros usuários, pares do usuário inicial;

d) gosto de diversos outros usuários, tomados a partir dos metadados dados pelos produtores/agregadores.

e) análise das reações emocionais dos usuários a cada música (com uso de redes neurais).

Através de cálculos complexos, cujas fórmulas não são tornadas públicas, pois constituem segredo de indústria, uma informação se junta a outra, criando uma cadeia chamada playlist, a qual pode ser renovada apenas pela recombinação dos fatores (além de novos dados inseridos através de cada categoria mencionada acima). Evidentemente, esse processo não resulta em escolhas perfeitas pelos algoritmos. No entanto, o erro é parte inerente (para não dizer fundamental) do processo. Como bem resume María F. Dorda:

Embora as pesquisas sobre Inteligência Artificial e Machine Learning estejam aplicando suas fórmulas matemáticas para se especializar na previsão do

8 Por recursividade (recursion), Paolo Totaro e Domenico Nino (2014, p. 30) assumem o sentido dado por Hofstadter de recursivo como o aninhamento de coisas dentro das coisas e suas variações. É como o fenômeno da repetição infinita de imagens refletidas em dois espelhos colocados opostos um ao outro. 
gosto dos internautas, o desenvolvimento de um processo mecânico que não falhe ainda está longe de ser alcançado. Não obstante, essa margem de erro é a chave para o próprio refinamento do algoritmo e, sem dúvida, leva o usuário ao conteúdo que não teria descoberto sem sua ajuda. $\mathrm{O}$ espaço em que o algoritmo se move é o do limite do gosto de cada usuário. Ou seja, o algoritmo explora os limites das "ilhas de gosto" do perfil de gosto de cada usuário e os destaca. Esta busca constante entre as categorias que identificam o gosto do usuário favorece a descoberta por acidente. Ao mesmo tempo, este rastreamento de identidade virtual e gostos já definidos é suportado por estatísticas derivadas do conjunto de internautas (DORDA, 2017, p. 27, tradução própria).

Cria-se, assim, uma aleatoriedade programada das músicas, em que o sistema é criado para prover um acesso aos conteúdos digitais de forma a parecer acaso e simular um acesso à diversidade de arquivos existentes. O objetivo é mobilizar as emoções dos ouvintes. $\mathrm{O}$ excesso de informações disponíveis (cada plataforma de streaming, por exemplo, vende-se a partir da oferta de "milhões" de arquivos) obriga a que se busque afetar o ouvinte para que continue escutando sempre e mais os arquivos sugeridos pela IA.

Não obstante, é crítico sublinhar, as novas sugestões que os algoritmos apresentam, como se fossem aleatórias, são derivações de proclividades passadas, de dados derivados do elenco apresentado acima, o que tende a apresentar tão somente variações de um grupo restrito de músicas. Afinal, os algoritmos sabem o que afeta ou não afeta as emoções dos usuários a fim de que consumam mais dentro da plataforma. Isso tende a criar, no limite, bolhas de gosto da qual parece ser muito difícil aos usuários escaparem. O paradoxo que se coloca, assim, é que, pese a abundância inédita de acesso a arquivos de música de diversas culturas, os algoritmos das plataformas digitais tendem a construir bolhas de gosto que se reforçam automaticamente, privando muitas outras possibilidades de consumo musical.

Como isso pode afetar a diversidade cultural no mercado fonográfico? Esses casos indicam a importância em se pensar as plataformas digitais de música como ecossistemas singulares, nos quais o gosto musical emerge de uma complexa interação entre relações sociais, afetos e função recursiva dos algoritmos. Isso acarreta uma série de questões: a circulação se tornou a etapa central para a aferição da diversidade cultural? Como medir a atividade dos algoritmos? Estes são capazes de manter a diversidade cultural por si mesmas? Ou se fazem necessárias leis que regulem sua atividade? Se assim for, como aplicar tal tipo de lei nacional em plataformas virtuais e globais? Enfim, como equilibrar a construção algorítmica do gosto com o objetivo de se proteger e fomentar a diversidade cultural em mercados específicos?

\section{Considerações finais}

Fica claro que os serviços de streaming apresentam um novo cenário para o debate sobre diversidade cultural nos mercados de comunicação e cultura, particularmente no fonográfico. $\mathrm{Na}$ era dos produtos físicos, o contexto que envolvia a produção, circulação e consumo das obras foi bem contemplado pelos estudos de diversidade cultural. $\mathrm{Na}$ era das plataformas digitais, ainda não está claro, de todo, o que deve ser estudado e, sobretudo, como deve ser estudado. Trata-se de lidar com uma economia na qual a etapa da produção se tornou menos problemática e a circulação ficou bem mais complexa. Mais do que isso, trata-se de lidar com tecnologias da informação (algoritmos) que não podem ser vistas como mero instrumentos para determinados fins, mas, sim, como agentes fundamentais na própria realização do mercado de música gravada. Sem os algoritmos das plataformas digitais, não se sabe o que há para ouvir e com quem se pode compartilhar o que se ouve. Presença nos arquivos dessas plataformas não significa estar acessível, legal e praticamente. Pelo contrário, como bem resumem Hoelck e Ranaivoson (2017, p. 25, tradução nossa): 
medida as plataformas estão dispostas a garantir que obras culturais marginais (criadas por criadores jovens, produzidos por produtores independentes ou originários de países pequenos) não só estejam disponíveis, mas também sejam promovidas de uma forma que pode compensar sua falta inicial de visibilidade. Em outras palavras, temos um risco em termos de Disparidade (isto é, há trabalhos marginais disponíveis?) E Equilíbrio (ou seja, todos os tipos de trabalhos têm igual disponibilidade e promoção?).

Logo, pode-se tratar de uma era da construção algorítmica do gosto musical.

Faz-se necessário, portanto, construir novas técnicas de pesquisa que abarquem o funcionamento dos algoritmos dessas plataformas digitais. Esse movimento é fundamental para rechaçar a ideia da cauda longa e cobrar das autoridades públicas políticas de comunicação e cultura (termos que não podem mais ser separados) que protejam e fomentem a diversidade cultural.

Enfim, o objetivo deste artigo não foi propor alguma nova metodologia de medição da diversidade cultural nas plataformas digitais, mas apontar esse cenário significativamente distinto do período analógico. Entende-se que é somente a partir desse reconhecimento que se tornará possível desenvolver novos métodos de análise que contemplem os desafios da era digital.

\section{Referências}

ALBORNOZ, Luis A.. "Medir la diversidad en la industria audiovisual: ¿una tarea posible? El trabajo promovido por la UNESCO”. In: ALBORNOZ, L. A.; GARCÍA LEIVA, M. T.. Diversidad e indústria audiovisual. México: FCE, 2017. P. 190-219.

ANDERSON, Chris. A cauda longa. Rio de Janeiro: Elsevier, 2006.

BURNETT, Robert; WEBER, Peter W.. NAPOLI, Phillip M.. "Deconstructing the "Concentration and diversity in popular music industry 1948-1986". Annual Meeting of the American Sociological Association, Aug., San Francisco, 1989.

CHRISTIANEN, Michael. "Cycles in symbol production? A new model to explain music industry". Popular Music, v. 14, n. 1, p. 5593, Jan. 1995.

DE MARCHI, Leonardo. A destruição criadora da indústria fonográfica brasileira, 1999-2009: dos discos físicos aos serviços digitais. Rio de Janeiro: Folio Digital, 2016.

DORDA, María F.. Serendipia programada: la construcción del gusto según las recomendaciones de Spotify. (Dissertação de mestrado). Getafe: Universidad Carlos III de Madrid, 2017.

GATES, Bill. A estrada do futuro. São Paulo: Cia das Letras, 1995.

HOELCK, Katharina; RANAIVOSON, Heritiana. "Threat or opportunity? Cultural diversity in the era of digital platforms in the EU". Quaderns del CAC, n. 40, vol. 20, p. 17-28, 2010.

KISCHINHEVSKY, Marcelo; VICENTE, Eduardo; DE MARCHI, Leonardo. "Em busca da música infinita: os serviços de streaming e os conflitos de interesse no mercado de conteúdos digitais". Revista Fronteiras, v. 17, n. 3, 2015.

KUSEK, David; LEONHARD, Gerd. The future of music. Boston: Berklee Press, 2005. 196 p.

LOPES, Paul D. "Innovation and diversity in the popular music industry, 1969 to 1990". American Sociological Review, v. 57, n. 1, p. 56-71, fev. 1992.

McQUAIL, Denis. La acción de los medios: los medios de comunicación y el interés público. Buenos Aires: Amorrortu Editores, 1998. concentration, diversity and innovation in the 
diversity principle". Journal of Communication, vol. 49, n. 4, p. 7-34, 1999.

PETERSON, Richard A.; BERGER, David G. "Cycles in symbol production: the case of popular music". American Sociological Review, vol. 40, p. 158-173, April 1975.

PETIT, Martí. "Génesis y evolución de los conceptos de 'cultura' y 'diversidad' desde los acuerdos de la OMC (1994) hasta la Convención de la UNESCO sobre la diversidade cultural (2005)". Revista de Estudios Políticos, Madrid, n. 156, p. 209-239, abril-junio 2012.

RANAIVOSON, Heritiana. "The determinants of the diversity of cultural expressions: an international quantitative analysis of diversity of production in the recording industry". Observatorio Journal, v. 4, n. 4, p. 215-249, 2010.

ROTHENBUHLER, Eric; DIMMICK, John W.. "Popular music: concentration and diversity in the industry". Journal of Communication, v. 32, p. 143-147, 1982.

STIRLING, Andrew. "On the economics and analysis of diversity". Electronic Working Papers Series, Brighton, n. 28, p. 1-134, 1998.

STOCZKOWSKI, Wiktor. "UNESCO's doctrine on cultural diversity: a secular soteriology?". Anthropology Today, v. 5, n. 3, p.7-11, 2009.

TOTARO, Paolo; NINO, Domenico. "The concept of algorithm as an interpretative key of modern rationality". Theory, Culture and Society, v. 31, n. 4, p. 29-49, 2014.

UNITED NATIONS EDUCATIONAL, SCIENTIFIC AND CULTURAL ORGANIZATION. Universal declaration on cultural diversity. Paris: UNESCO, 2001.

Convention on the protection and promotion of the cultural expressions. Paris: Unesco, 2005.
VARIAN, Hal R.; SHAPIRO, Carl. A economia da informação: como os princípios econômicos se aplicam à era da internet. Rio de Janeiro: Campus, 1999.

.

